\title{
How Location Shapes Environmental Awareness Among Inhabitants of Eastern Poland - An Empirical Study
}

\author{
Wiesław Piekarski ${ }^{1 *}$, Monika Stoma ${ }^{1}$, Agnieszka Dudziak ${ }^{1}$, \\ Dariusz Andrejko², Beata Ślaska-Grzywna² \\ ${ }^{1}$ University of Life Sciences in Lublin, Department of Power Engineering and Transportation, \\ Głęboka 28, 20-612 Lublin, Poland \\ ${ }^{2}$ University of Life Sciences in Lublin, Department of Biological Bases of Food and Feed Technologies \\ Głęboka 28, 20-612 Lublin, Poland
}

Received: 9 February 2015

Accepted: 16 November 2015

\begin{abstract}
Environmental awareness and its perception by humans is not an entirely clear issue, and the extent to which problems related to ecology and environmental protection are recognized raises many doubts. Our paper presents findings obtained from the authors' own questionnaire made up of 46 statements carrying positive connotations. A five-level Likert scale was applied to evaluate statements; respondents were asked to specify which level on the scale best corresponded with their view on each statement. In order to identify variables differentiating between specific groups of respondents, the data gathered from questionnaires was subject to a type of statistical analysis called discriminant function analysis. The aim of the study was to analyse links between the place of living and evaluation of the natural environment, certain factors affecting environmental awareness, and willingness to undertake environment-friendly actions by people living in Eastern Poland. The discriminant function analysis enabled categorization of opinions and attitudes of the respondents according to their place of living, indicating that their diversified nature results from the place they inhabit. The analysis revealed that a grouping variable used to categorize places of living has statistically significant discriminatory power. Inhabitants of large cities are interested in the subject of environmental protection, but they pay less attention to other aspects of "environmental awareness" than people living in small towns or in the countryside, which is largely attributable to their close contact with nature.
\end{abstract}

Keywords: environmental awareness, environmental protection, discriminant function analysis, environment-friendly actions

\section{Introduction}

Environmental awareness is an expression of a knowledge of the natural environment shared by an individual or society; it is also manifested in an ability

*e-mail: wieslaw.piekarski@up.lublin.pl to discern phenomena, their interdependencies, causes or possible effects, and to take concrete environmental actions. It is based on the understanding of mechanisms governing nature, knowledge of the limits of its exploitation, as well as constraints and capabilities for recognizing environment-related problems [1]. The source literature, however, still fails to provide the only 
one universal and generally acknowledged definition of this term [2].

Development of human environmental awareness is a complex process since it depends on numerous factors, including social and economic levels, people's mindset and culture, strategies relating to local and worldwide actions, and a degree of environmental degradation. It is also shaped under the influence of generally accepted social norms, environmental education, state actions, personal observations, and experiences [3]. Of no less importance seem descriptive attributes of inhabitants, including their place of living, age, education, or standard of living $[4,5]$. Authors also call attention to dependence of the level of environmental awareness on the specific nature of problems connected with their local scope of occurrence [6-8].

The higher environmental awareness an individual reveals, the more often he takes conscious actions that contribute to environmental protection. The world recognizes global threats to the environment such as climate change, air pollution, or water pollution, but local problems, e.g., relating to the adverse impact of transport infrastructure, are also pointed out $[9,10]$.

Furthermore, a high level of environmental awareness determines purchasing decisions in society - environment-oriented customers choosing products that are least detrimental to the natural environment [5, 11]. This, in consequence, affects producers who are to some extent forced to switch to more environmentfriendly manufacturing processes and to take into account environmental considerations in all stages of the product lifecycle $[5,12]$. Furthermore, the relevance of recycling in this kind of studies [13] or the significance of the legal regulations governing the natural environment [14] should be highlighted.

The importance of the problem is further emphasized by the fact that both current as well as future quality of the human environment depends on environmental awareness and environment-friendly attitudes and behaviour patterns [15]. That's why environmental scientists are increasingly interested in better understanding how people cognitively organize their beliefs and attitudes toward environmental change in order to identify key motives and barriers that stimulate or prevent action [16].

Taking into consideration constant change, we already speak of the ecological culture in society. Therefore, our study aimed to analyze dependence between the place of living and evaluation of the natural environment, as well as a willingness to take environment-friendly actions among people living in Eastern Poland.

\section{Materials and Methods}

The data gathered from the study based on a structured questionnaire served as source material. The study's starting point consisted in the preparation of a list of determinants that enabled a description of environmental awareness and environment-friendly actions. These determinants have been grouped into five main thematic areas (Table 1):

1. Assessing the state of the local natural environment.

2. Assessing the environmental awareness of residents.

3. Assessing individual actions to the extent of the protection of the natural environment.

4. Assessing the effectiveness of the local authorities' actions in the field of environmental protection.

5. Knowledge and its sources concerning the natural environment and its protection.

The list was compiled on the basis of research reported in the source literature and an analysis of the specific nature of the problem in question.

Given the fact that interrelations between investigated issues were unknown, researchers adopted an exploratory approach that involved the selection of such attributes of an object that would describe it in the most general terms.

The questionnaire study was carried out in 2014 and included 188 respondents. In order to determine the number of respondents, researchers took into account the criteria applied to methods of the statistical analysis because such analysis requires a sample of at least 100-200 persons from the whole population [17]. The study was conducted with the use of a sampling method and respondents were selected based on the random sampling method. Surveys were distributed among the respondents in two ways - in a traditional form and via the Internet. Questionnaires were anonymous and each respondent was informed in advance of the general aim of the study.

The designed statistical measurement tool (questionnaire) was made up of 46 statements carrying positive connotations, whose meanings corresponded to features included in the list of primary determinants. Statements were evaluated with the use of the five-level Likert scale, in which a number of points is ascribed to every type of response (from 1 - strongly disagree, to 5 - strongly agree). Positions 1 and 2 on the scale signified negative responses, positions 4 and 5 were positive, while position 3 was neutral and meant "neither agree nor disagree." In each item, respondents were asked to tick the level on the scale that best reflected their attitude towards it. Questionnaires also included a set of demographic questions that helped identify respondents' descriptive characteristics, including sex, age, education, place of living, and profession.

In order to identify variables differentiating between specific groups of respondents, the data collected from questionnaires was subject to a type of statistical analysis called discriminant function analysis [18]. Variables that characterized the whole population and were included in the set of demographic questions attached to the questionnaire served as grouping variables. Analyses took into consideration one of the grouping variables - the place of living. On the basis of the information about each respondent and his or her membership in a given group, it was possible to compute a discriminant function for the grouping variable under analysis so as to maximize intergroup variability relation to intragroup variability, and to obtain the possibly similar values of the membership 
Table 1. List of determinants describing environmental awareness and environment-friendly actions.

\begin{tabular}{|c|c|}
\hline \multicolumn{2}{|r|}{ Assessing the state of the local natural environment } \\
\hline 1. & positive assessment of the general state of the environment \\
\hline 2. & improving the general state of the environment within the last five years \\
\hline 3. & air pollution not present or slight \\
\hline 4. & water pollution not present or slight \\
\hline 5. & soil degradation not present or slight \\
\hline 6. & no significant environmental pollution by industry \\
\hline 7. & no significant noise (traffic or industrial) \\
\hline 8. & appropriate waste management (no illegal dumps, littering the forest, burning garbage, etc.) \\
\hline 9. & controlled discharge of sewage from households \\
\hline 10. & introducing appropriate agricultural practices and proper fertilizers by farmers \\
\hline 11. & protection of valuable natural areas \\
\hline 12. & control of forest areas and no excessive deforestation \\
\hline 13. & high public awareness of environmental protection \\
\hline \multicolumn{2}{|r|}{ Assessing the environmental awareness of the residents } \\
\hline 14. & residents' sense of responsibility for the environment \\
\hline 15. & undertaking appropriate social actions to protect the environment \\
\hline 16. & sorting of waste by residents \\
\hline 17. & using eco-friendly means of transport, e.g., a bike or on foot by borough inhabitants \\
\hline 18. & limiting consumption of media \\
\hline 19. & the use of reusable bags while shopping by residents of the borough \\
\hline 20. & social involvement in activities for environmental protection \\
\hline \multicolumn{2}{|r|}{ Assessing individual actions for the protection of the environment } \\
\hline 21. & high individual awareness regarding environmental protection \\
\hline 22. & individual sense of responsibility for the environment \\
\hline 23. & undertaking appropriate individual actions for environmental protection \\
\hline 24. & a proposal of introducing a small voluntary tax to protect the environment \\
\hline 25. & sorting of waste in the household \\
\hline 26. & individual exploitation of eco-friendly means of transport, e.g., a bike or on foot \\
\hline 27. & individual limiting consumption of media (e.g., water) \\
\hline 28. & individual use of reusable bags (organic materials, paper) while shopping \\
\hline 29. & individual participation in environmental protection activities \\
\hline \multicolumn{2}{|r|}{ Assessing the effectiveness of the local authorities' actions in the field of environmental protection } \\
\hline 30. & undertaking sufficient actions by the authorities regarding environmental protection \\
\hline 31. & undertaking sufficient actions by the authorities regarding environmental protection in the voivodship \\
\hline 32. & organizing actions aimed at promoting environmental protection by the municipal authorities \\
\hline 33. & organizing actions aimed at promoting environmental protection by the voivodship authorities \\
\hline 34. & a need for more activities aimed at raising the ecological awareness of residents of the borough/voivodship \\
\hline 35. & a need for more activities aimed at improving environmental improvement of the borough/voivodship \\
\hline 36. & proposing higher penalties/fines for pollution to be introduced by authorities \\
\hline 37. & more containers for sorting waste needed \\
\hline
\end{tabular}


Continued

\begin{tabular}{|c|c|}
\hline \multicolumn{2}{|r|}{ Knowledge and its sources concerning the environment and its protection } \\
\hline 38. & $\begin{array}{c}\text { individual participation in local ecological education campaigns (e.g. picnics, organic festivals, 'Clean Up the World' } \\
\text { activities, etc.) }\end{array}$ \\
\hline 39. & adequate transfer information about ecology and environmental protection by the education system \\
\hline 40. & acquiring knowledge about the condition and environmental protection issues from the media \\
\hline 41. & $\begin{array}{c}\text { acquiring knowledge about the condition and environment protection issues from various actions and environmental } \\
\text { campaigns }\end{array}$ \\
\hline 42. & $\begin{array}{c}\text { acquiring knowledge about the condition and the environmental protection issues from the information provided by the } \\
\text { office of the city/municipality }\end{array}$ \\
\hline 43. & knowledge on the concept of 'sustainable development' \\
\hline 44. & proposing high penalties for businesses that are major pollutants \\
\hline 45. & greater importance of environmental protection against pollution than municipal/businesses income growth \\
\hline 46. & the environment is more important than economic growth \\
\hline
\end{tabular}

Source: the authors' own studies.

function with the possibly highest heterogeneity preserved between groups.

The discriminant function enabled distribution of new observations into categories by categorical variable used to create functions. The function - an equation predicting group membership - was defined by the following formula:

$$
\mathrm{Y}=\alpha_{0}+\alpha_{1} \mathrm{X}_{1}+\alpha_{2} \mathrm{X}_{2}+\ldots+\alpha_{\mathrm{p}} \mathrm{X}_{\mathrm{p}}
$$

...where $\mathrm{Y}$ is the grouping variable used to determine membership of the individual to a given segment; $\mathrm{Xi}$ is the independent variable, a descriptor of membership of the individual to a given segment $(i=1, \ldots, p) ; \alpha_{0}$ is constant and $\alpha \mathrm{i}$ is the unstandardized discriminant coefficient for the discriminant function, or the rule for membership for the individual to a given segment $(i=1, \ldots, p)$. The discriminant function analysis included three stages:

1) stepwise analysis,

2) chi-square test,

3) canonical correlation analysis.

As a result of the stepwise analysis, it was possible to identify variables (used to build the model of the discriminant function) that served best as discriminators of a given group. It was also possible to define values of Wilks' lambda, partial lambda, and F-value, which indicates statistical significance for group discrimination of a given variable.

Wilks' lambda is a standard test statistic used to determine whether the discriminatory power of the current model is statistically important. It provides information about the proportion of total variability whose group differences are not accounted for, and indicates to what extent values of functions can be confounded by other variables than membership in differentiated groups. Wilks' lambda is defined by the formula:

$$
\lambda=\frac{q_{R}}{q}
$$

...where $q_{R}$ is intragroup variability for the membership function and $q$ is total variability for the membership function, which is the sum of inter- $\left(_{\mathrm{qG}}\right)$ and intra-group $\left(\mathrm{q}_{\mathrm{R}}\right)$ variability, $q=\mathrm{q}_{\mathrm{G}}+\mathrm{q}_{\mathrm{R}}$.

The F-statistic, characterized by Fisher-Snedecor distribution with $N-l-p$ and $k-1$ degrees of freedom, was calculated from the equation:

$$
F=\frac{N-k-p}{k-1} \times \frac{\frac{1-\lambda_{P}}{\lambda_{P}}}{\frac{\lambda_{P+1}}{\lambda_{P}}}
$$

...where:

$N$ - number of objects

$k$ - number of classes

$p$ - number of variables in a function

$\lambda_{p}$ - value of Wilks' lambda before adding a variable

$\lambda_{p+1}^{p}$ - value of Wilks' lambda after adding a variable

The next stage of the discriminant function analysis involved verification, with the use of a chi-square test, of statistical significance of the models built in the previous stage. The chi-square statistic $\left(\chi^{2}\right)$ was calculated by the following formula:

$$
\chi^{2}=\left(N-\frac{k+p}{2}-1\right) \ln \left(\frac{1}{1+\lambda}\right)
$$

...where:

$N$ - number of observations

$k$ - number of groups

$p$ - number of diagnostic variables

$\lambda$ - value of Wilks' lambda

The higher the values of the chi-square statistic, the more solid the basis for considering classification results 
to be significant. Analyses investigated only significant functions (the adopted criterion level was $\alpha=0.05$ ).

The last stage of discriminant function analysis was the canonical analysis that enabled determination of the number of statistically significant canonical roots, parameters of the discriminant function, and eigenvalues of every function. Standardized coefficients for canonical variables were calculated based on standardized independent variables with their means $=0$ and variances $=1$. They indicate how significant respective variables are to distribute objects into groups, while canonical averages make it possible to define the discriminatory nature for each category within the grouping variable.

The statistical analysis of results was carried out with the use of Statistica 10 software.

\section{Results}

The data gathered from the empirical material was subject to the statistical analysis (in order to describe the population structure and specific variables) whose results were presented in graphic, tabular, and descriptive forms.

The information gathered from our own studies enabled a description of respondents in terms of grouping variables such as sex, age, education, place of living, and profession. Given the subject matter of the paper, demographic and social characteristics were limited to one variable, i.e., the place of living. The survey included 188 respondents from eastern Poland, of whom 89 persons $(47.3 \%)$ live in the countryside, 47 (25\%) live in cities of up to 300,000 inhabitants, and 52 persons $(27.7 \%)$ live in cities of more than 300,000 inhabitants.

In line with the adopted research methodology, the grouping variable relating to the place of living was subject to a discriminant function analysis (three categories: a countryside, b-city of up to 300,000 inhabitants, c - city of more than 300,000 inhabitants) with a view to determining which variables of dimensional summary statistics of the examined model discriminate between two or more groups for specific categories of the variable. As an outcome of the forward stepwise analysis it was possible to build an overall model defined by 11 variables. Table 2 presents results of the discriminant function analysis carried out for the "place of living" grouping variable (columns 1-6).

Variables identified in the forward stepwise analysis were presented in the step-by-step order that they were incorporated in the model. The second column presents values for Wilks' lambda after including the variable in the model, while the third column presents values of partial Wilks' lambda for the unique contribution of the respective variable to the discriminatory power with regard to groups. Wilks' lambda may be converted into a standard $F$-value (see column No. 4 ), and for each $F$-value their respective $p$-values (see column No. 5) and the tolerance value (column No. 6), computed as $1-\mathrm{R}^{2}$ for the variable with all other variables in the model, were calculated. The tolerance value is a measure of the respective variable's redundancy. Overall values of statistics used in the model: $\lambda=0.47523$ and $F(22.35)=7.168738(p<0.0000)$ indicate a statistically significant discriminatory power of the model.

Analysis of the results presented in Table 2 (column No. 3) indicate that values of partial Wilks' lambda for this model are greater than 0.9029 , i.e., close to 1 , which means they do not have significant discriminatory power. Variable No. 18 makes the greatest contribution to discrimination ("Increasingly more people in my municipality try to reduce the use of media"), and variable No. 13 ("In my place of living people are characterized by high environmental awareness with regard to environmental protection").

In the investigated case, the variable grouping "the place of living" is broken down into three categories, hence two discriminant functions are subject to canonical analysis. Table 3 (lines 1-6) present results obtained when the significance of discriminant functions described by the 11 primary attributes mentioned above were verified. According to them, both functions 1 and 2 are statistically significant, which makes it possible to reject the null hypothesis that there is no discrimination between categories of the variable related to the place of living.

Standardized coefficients of discriminant variables are presented in Table 2 (column Nos. 7 and 8).

Discriminant function No. 1 for the "place of living" grouping variable accounts for the large percentage of inter-group variance (75\%). It is computed as follows:

$$
\begin{aligned}
\mathrm{Y}_{1}= & 0.66 \mathrm{x}_{4}-0.63 \mathrm{x}_{13}+0.60 \mathrm{x}_{41}-0.52 \mathrm{x}_{9} \\
+ & 0.47 \mathrm{x}_{12}-0.39 \mathrm{x}_{18}-0.38 \mathrm{x}_{33}-0.34 \mathrm{x}_{8} \\
& +0.27 \mathrm{x}_{11}+0.12 \mathrm{x}_{20}+0.07 \mathrm{x}_{24}
\end{aligned}
$$

The results show that in the case of the received discriminant function, variable Nos. 4, 13, 41, 9, 12, 18, and 33 made the greatest contribution to discrimination. Therefore, these are major attributes that discriminate between investigated attitudes.

Then, discriminant function No. 2 for the "place of living" grouping variable takes the following form:

$$
\begin{gathered}
\mathrm{Y}_{2}=0.75 \mathrm{x}_{20}+0.70 \mathrm{x}_{24} \mathrm{v} 0.69 \mathrm{x}_{18} \mathrm{v} \\
0.47 \mathrm{x}_{11}-0.36 \mathrm{x}_{41}+0.33 \mathrm{x}_{8}-0.33 \mathrm{x}_{9}+ \\
0.20 \mathrm{x}_{33}+0.12 \mathrm{x}_{4}+0.10 \mathrm{x}_{12}-0.07 \mathrm{x}_{13} .
\end{gathered}
$$

The analysed data indicates that in the case of discriminant function No. 2, discrimination between investigated attitudes is made chiefly based on primary attributes: 20, 24, 18, 11, 41, 8, and 9.

Although the second function has relatively less discriminatory power, it is still significant and thus makes it possible to determine the nature of discrimination. Table 3 (lines 7-9) presents means for canonical variables included in the respective model of the discriminant function (average values of discriminant variables for different categories within "the place of living"). Differences between the means are larger for the first of the two discriminant variables. The first function discriminates 
Table 2. Discriminant function analysis for the "place of living" grouping variable and its standardized coefficients.

\begin{tabular}{|c|c|c|c|c|c|c|c|}
\hline 1 & 2 & 3 & 4 & 5 & 6 & 7 & 8 \\
\hline Variable & $\begin{array}{l}\text { Wilks' } \\
\lambda\end{array}$ & $\begin{array}{l}\text { Partial } \\
\text { Wilks' } \\
\lambda\end{array}$ & $\begin{array}{l}\text { F-to } \\
\text {-remove } \\
(2.175)\end{array}$ & $\mathrm{p}$-value & Toler. & Root 1 & Root 2 \\
\hline $\begin{array}{l}\text { 9. "Controlled sewage disposal system operates in my } \\
\text { place of living" }\end{array}$ & 0.5245 & 0.9060 & 9.076 & 0.0001 & 0.7011 & -0.5239 & -0.3281 \\
\hline $\begin{array}{l}\text { 11. "High-nature value areas are not subject to } \\
\text { degradation in my place of living (in the form of } \\
\text { deforestation, or excessive housing development)" }\end{array}$ & 0.4997 & 0.9509 & 4.509 & 0.0123 & 0.6820 & 0.2677 & -0.4727 \\
\hline $\begin{array}{l}\text { 24. "In my opinion, a small amount of the voluntary } \\
\text { environment tax should be introduced" }\end{array}$ & 0.5156 & 0.9217 & 7.436 & 0.0008 & 0.8372 & -0.0716 & 0.6961 \\
\hline $\begin{array}{l}\text { 18. "Increasingly more people in my municipality try } \\
\text { to reduce the use of media" }\end{array}$ & 0.5263 & 0.9029 & 9.409 & 0.0001 & 0.6340 & -0.3947 & -0.6853 \\
\hline $\begin{array}{l}\text { 20. "Increasingly more people in my municipality take } \\
\text { part in actions for environmental protection" }\end{array}$ & 0.5098 & 0.9322 & 6.369 & 0.0021 & 0.6081 & 0.1208 & 0.7477 \\
\hline 4. "Water in my place of living is not polluted" & 0.5383 & 0.8828 & 11.616 & 0.0000 & 0.6399 & 0.6599 & 0.1209 \\
\hline $\begin{array}{l}\text { 41. "I learn about environment and its protection from } \\
\text { various eco-friendly actions and campaigns" }\end{array}$ & 0.5386 & 0.8823 & 11.670 & 0.0000 & 0.6819 & 0.5986 & -0.3578 \\
\hline $\begin{array}{l}\text { 13. "People in my place of living have a high level of } \\
\text { awareness of environmental protection" }\end{array}$ & 0.5256 & 0.9042 & 9.268 & 0.0001 & 0.5832 & -0.6277 & -0.0735 \\
\hline $\begin{array}{l}\text { 12. "In my place of living forested terrains are under } \\
\text { control and there is no excessive logging operations } \\
\text { are carried out there" }\end{array}$ & 0.5076 & 0.9361 & 5.971 & 0.0031 & 0.6718 & 0.4739 & 0.1040 \\
\hline $\begin{array}{l}\text { 33. "Provincial authorities in my place of living } \\
\text { organise actions to promote environmental protection" }\end{array}$ & 0.5055 & 0.9400 & 5.581 & 0.0044 & 0.8996 & -0.3769 & 0.2032 \\
\hline $\begin{array}{l}\text { 8. "Good waste management system operates in my } \\
\text { place of living (no illegal waste dump, littering of } \\
\text { forests, burning of rubbish)" }\end{array}$ & 0.4989 & 0.9525 & 4.359 & 0.0141 & 0.6965 & -0.3398 & 0.3281 \\
\hline Eigenvalue & - & - & - & - & - & 0.7072 & 0.2326 \\
\hline Accumulated proportion & - & - & - & - & - & 0.7525 & 1.0000 \\
\hline
\end{tabular}

Source: the authors' own studies.

primarily between people living in the countryside and people from large cities of more than 300,000 inhabitants. The second function, in turn, discriminates between people living in small and medium-size or large cities.

The nature of discrimination was depicted also in graphic form (Fig. 1). The analysis of the graph reveals that coordinates of the majority of items against the first variable (axis), which represent people living in the countryside, have higher values than corresponding coordinates of items referring to people living in large cities (of more than 300,000 inhabitants). Relative to the first discriminatory variable, coordinates of points representing people living in cities of 100-300,000 inhabitants have high values in the coordinate volatility interval for people living in large cities, and low values for those from the countryside.

In the case of the second discriminatory variable, it is observed that, relative to the second discriminatory variable (axis), coordinates of the majority of items representing people living in cities of 100-300,000 inhabitants have much higher values than corresponding

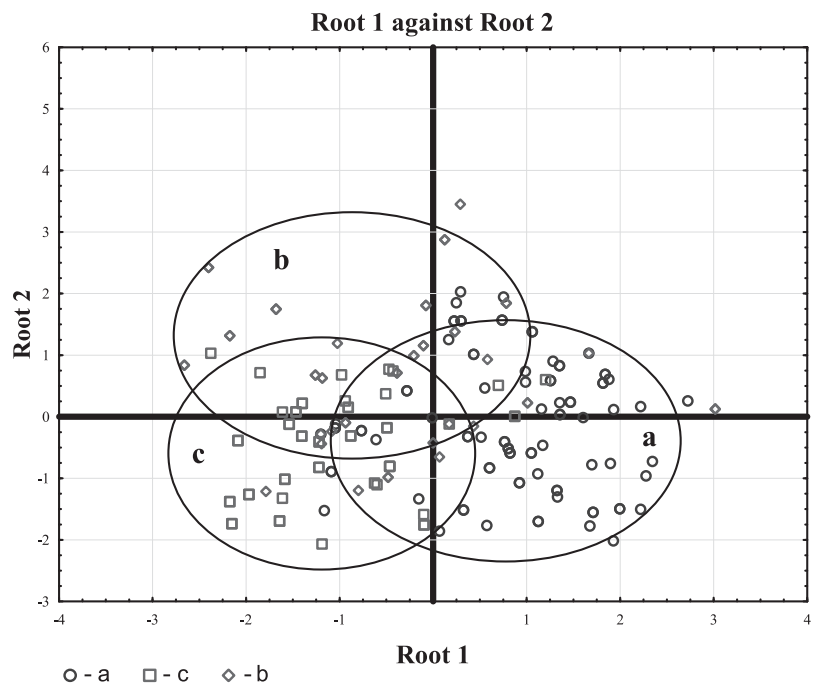

Fig. 1 The nature of discrimination for the "place of living" grouping variable (a - countryside, b - city of 100-300,000 inhabitants, $\mathrm{c}-$ cities of $>300,000$ inhabitants). Source: own study. 
Table 3. Chi-square test values and means of canonical variables for the "place of living" grouping variable.

\begin{tabular}{|c|c|c|c|}
\hline \multicolumn{4}{|c|}{ Chi-square test value } \\
\hline 1 & Eigenvalue & 0.707169 & 0.232601 \\
\hline 2 & Canonical R & 0.643611 & 0.434405 \\
\hline 3 & Wilks' lambda & 0.475227 & 0.811293 \\
\hline 4 & $\chi^{2}$ & 133.9134 & 37.6428 \\
\hline 5 & df & 22.00000 & 10.00000 \\
\hline 6 & p-value & 0.000000 & 0.000044 \\
\hline \multicolumn{4}{|c|}{ Means of canonical variables } \\
\hline 7 & $\begin{array}{c}\text { a - countryside } \\
\text { inhabitants }\end{array}$ & 0.847684 & -0.135117 \\
\hline 8 & $\begin{array}{c}\text { b- cities of } 100-300,000 \\
\text { inher| }\end{array}$ & -0.438273 & 0.789613 \\
\hline 9 & $\begin{array}{c}\text { c - cities of }>300,000 \\
\text { inhabitants }\end{array}$ & -1.05471 & -0.48243 \\
\hline
\end{tabular}

Source: the authors' own studies.

coordinates of the items representing other categories within the place of living.

Taking into account standardized coefficients for canonical variables (Table 2) and their means (Table 3), the discriminant function analysis for the place of living may be summarized as follows: variable Nos. 4, 41, 12, 11 , and 20 characterize people living in the countryside and differentiate them from people living in large cities who, in turn, are characterized by variable Nos. 13, 9, 18, 8,33 , and 24 .

\section{Discussion of Results}

The analysis of the study's results show that the level of environmental awareness developed by an individual or society is conditioned by numerous variables; one of the most important variables includes the state of the natural environment in which a respective individual or society functions. The relationship between place attachment and pro-environmental behaviors has been examined in the literature. While findings are conflicting, place attachment has been shown to be associated with less (even null), but also with more, pro-environmental behaviors [19]. Certain studies indicate that the level of environmental awareness is higher among people living in relatively more environmentally degraded regions [20]. However, on the basis of results obtained from the authors' own studies, it can be inferred that certain attitudes and willingness to take actions aiming to protect the natural environment are revealed by people who live in areas diversified in terms of the degree of urbanization, but they are fostered by various circumstances.

On the basis of the analysis results, it may be stated that people living in the countryside are characterized primarily by variable Nos. $4,41,12,11$, and 20 . This means that they pay attention particularly to issues concerning their place of living (no water pollution, protection of high-nature value areas, control over forests, participation in municipal actions for environmental protection), which largely results from their close contact with nature. People living in large cities are also interested in environmental issues, but they are concerned with other aspects of "environmental awareness" (related to their place of living), including controlled household sewage disposal, reduction of the use of media, actions organized by provincial authorities to promote environmental protection, willingness to pay small amounts of a voluntary environmental tax (such persons are characterized by variable Nos. 13, 9, 18, 8, 33, and 24).

The survey proves the thesis about dependence between the evaluation of the natural environment and the place of living and, consequently, the degrees of industrialization and urbanization [21-25]. Respondents revealed certain characteristics of regionalism, i.e., more thorough knowledge about one's own place of living. Inhabitants of heavily degraded areas, affected by extensive anthropogenic processes, have developed environmental awareness based on observations of the effects of adverse impact on the natural environment [26]. People living in protected areas develop a sense of environmental awareness on the basis of their own positive experiences and observations, as well as by comparing their place of living with areas under strong and negative human influence $[27,28]$.

The conducted research, obtained results, and the conclusions drawn on the basis thereof make it possible to formulate recommendations for people taking decisions to the extent of environmental awareness of the residents, e.g., the authorities within a given municipality or a region. Getting to know the variables that determine the degree of environment-related awareness of individuals, depending on their place of residence, and as a consequence the condition of the environment in which they live (the degree of urbanization and degradation of the environment), can be helpful in developing and implementing some adequate educational measures.

\section{Conclusions}

The studies described in the source literature as well as the obtained results and discussion of the analysis showed that respondents' attitudes to the natural environment and environmental protection differ depending on their place of living. On the basis of the discriminant function analysis, it is possible to state that a grouping variable for the place of living has statistically significant discriminatory power (Wilks' lambda for the grouping variable was 0.47523). Attitudes of people living in bigger towns are conditioned primarily by variable Nos. $13,9,18,8,33$, and 24 , whereas of those living in the countryside by variable Nos. $4,41,12,11$, and 20 . This means that people living in the countryside pay attention 
particularly to issues concerning their place of living (no water pollution, protection of high-nature value areas, control over forests, participation in municipal actions for environmental protection), which may largely stem from their close contact with nature. However, people living in large cities are also interested in environmental issues, but they are concerned with other aspects of "environmental awareness," including controlled household sewage disposal, appropriate waste management, reduction of the use of media, actions organized by provincial authorities to promote environmental protection, and willingness to pay small amounts of a voluntary environmental tax. The obtained results may constitute the basis for the decisive bodies of local authorities to the extent of promoting environmental actions by means of different types of social campaigns aimed at residents of both rural and hugely urbanized areas.

\section{References}

1. BURGER T. Conflict and cooperation. Environmental awareness and society's attitudes. [in:] Environmental awareness and social movements of "the Greens" in Poland. Mirowski W (ed.). Wyd. IFiS PAN, Warszawa, 51, 1999 [In Polish].

2. DACKO M. Systems Dynamics in Modeling Sustainable Management of the Environment and Its Resources. Pol. J. Environ. Stud. 19 (4), 699, 2010.

3. ÖZDEN M. Environmental Awareness and Attitudes of Student Teachers: An Empirical Research. Int. Res. Geogr. Environ. Educ. 17 (1), 40, 2008.

4. BERNATH K., ROSCHEWITZ A. Recreational benefits of urban forests: Explaining visitors' willingness to pay in the context of the theory of planned behavior. J. Environ. Manage. 89 (3), 155, 2008.

5. LIU Z., ANDERSON T. D., CRUZ J. M. Consumer environmental awareness and competition in two-stage supply chains. Eur. J. Oper. Res. 218, 602, 2012.

6. HOUGHTON J. Place and the implications of 'the local' for sustainability: an investigation of the Ugu District Municipality in South Africa. Geoforum 36 (4), 418, 2005.

7. SCHULTZ P.W., SHRIVER C., TABANICO J., KHAZIAN A.M. Implicit connections with nature. J. Environ. Psychol. 24, 31, 2004.

8. MÄLGAND M., BAY-MORTENSEN N., BEDKOWSKA B., HANSEN F. N., SCHOW M., THOMSEN A. A., HUNKA A.D. Environmental awareness, the Transition Movement, and place: Den Selvforsynende Landsby, a Danish Transition initiative. Geoforum 57, 40, 2014.

9. SZYSZLAK-BARGŁOWICZ J., SŁOWIK, T., ZAJACC G., PIEKARSKI W. Inline Plantation of Virginia Mallow (Sida hermaphrodita R.) as Biological Acoustic Screen. Rocz. Ochr. Sr. 15 (1), 524, 2013.

10. SZYSZLAK-BARGŁOWICZ J., SŁOWIK, T., ZAJĄC G., PIEKARSKI W. The Content of Heavy Metals in the Drainage Ditches by Communication Routes. Rocz. Ochr. Sr. 15 (3), 2309, 2013 [In Polish].

11. ZHANG L., WANG J., YOU J. Consumer environmental awareness and channel coordination with two substitutable products. Eur. J. Oper. Res. 241, 63, 2015.
12. KHOSHNEVISAN B., BOLANDNAZAR E., SHAMSHIRBAND S., SHARIATI H.M., ANUAR N.B., KIAH M. Decreasing environmental impacts of cropping systems using life cycle assessment (LCA) and multiobjective genetic algorithm. J. Clean. Prod. 86, 67, 2015.

13. CRUZ N., FERREIRA S., CABRAL M., SIMÕES P., MARQUES R. Packaging waste recycling in Europe: is the industry paying for it? Waste Manage. 34 (2), 298, 2014.

14. MARQUES R., SIMÕES P., PIRES J. Performance benchmarking in utility regulation: the worldwide experience. Pol. J. Environ. Stud. 20 (1), 125, 2011.

15. SEGARRA-OÑA M., PEIRÓ-SIGNES A., MONDÉJARJIMÉNEZ J. Identifying Variables Affecting the Proactive Environmental Orientation of Firms: An Empirical Study. Pol. J. Environ. Stud. 22 (3), 873, 2013.

16. HOYOS D., MARIEL P., HESS S. Incorporating environmental attitudes in discrete choice models: An exploration of the utility of the awareness of consequences scale. Sci. Total Environ. 505, 1100, 2015.

17. ZAKRZEWSKA M. Factor analysis in the construction and verification of the psychological models, Wyd. Nauk. UAM, Poznań, 40, 1994 [In Polish].

18. LAWSON R.A. Discriminant analysis - an aid to market segment description. Eur. J. Marketing 14 (7), 387, 1980.

19. SCANNELL L., GIFFORD R. The relations between natural and civic place attachment and pro-environmental behavior. J. Environ. Psychol. 30 (3), 289, 2010.

20. YU X. Is environment 'a city thing' in China? Ruraleurban differences in environmental attitudes. J. Environ. Psychol. 38, 39, 2014.

21. ALI R., SINHA B. A Study of Environmental Awareness and Ecological Behaviour among Female B.Ed. Students. An International Multidisciplinary Refereed E Journal 2 (1), 41, 2013.

22. ANTON C.E., LAWRENCE C. Home is where the heart is: The effect of place of residence on place attachment and community participation. J. Environ. Psychol. 40, 451, 2014.

23. RAMKISSOON H., SMITH L. D.G., WEILER B. Testing the dimensionality of place attachment and its relationship with place satisfaction and proenvironmental behaviours: A structural equation modelling approach. Tourism Manage. 36, 552, 2013.

24. SOINI K., VAARALA H., POUTA E. Residents' sense of place and landscape perceptions at the rural-urban interface. Landscape Urban Plan. 104, 124, 2012.

25. CARRUS G., SCOPELLITI M., FORNARA F., BONNES M., BONAIUTO M. Place attachment, community identification, and pro-environmental engagement. [In:] M. Lynne, \& D.-W. Patrick (Eds.), Place attachment: Advances in theory, methods and applications. London and New York: Routledge, 176, 2013.

26. NYCZ-WRÓBEL J. Environmental awareness and the resulting risks to the environment (on the example of opinion of residents of the Podkarpackie Province), Zeszyty Naukowe Politechniki Rzeszowskiej, Ekonomia i Nauki Humanistyczne, 19 (286), 63, 2012 [In Polish].

27. CHENG J. C. H., MONROE M. C. Connection to nature. Environ. Behav. 44(1), 31-49, 2012.

28. HUNTER M.R. Impact of ecological disturbance on awareness of urban nature and sense of environmental stewardship in residential neighborhoods. Landscape Urban Plan. 101, 131, 2011 